\title{
Icariin promotes bone formation via the BMP-2/Smad4 signal transduction pathway in the hFOB 1.19 human osteoblastic cell line
}

\author{
WENNA LIANG $^{1 *}$, MUNAN LIN $^{2 *}$, XIHAI LI $^{3}$, CANDONG LI $^{1}$, BIZHENG GAO $^{1}$, HUIJUAN GAN $^{1}$, \\ ZHAOYANG YANG ${ }^{1}$, XUEJUAN LIN ${ }^{1}$, LINGHONG LIAO ${ }^{1}$ and MIN YANG ${ }^{1}$
}

\author{
${ }^{1}$ Research Base of Traditional Chinese Medicine Syndrome, Fujian University of Traditional Chinese Medicine, Fuzhou 350122; \\ ${ }^{2}$ Department of Traditional Chinese Medicine, Fuzhou General Hospital of Nanjing Military Command, Fuzhou 350025; \\ ${ }^{3}$ Academy of Integrative Medicine, Fujian University of Traditional Chinese Medicine, Fuzhou 350122, P.R. China
}

Received April 28, 2012; Accepted June 23, 2012

DOI: $10.3892 /$ ijmm.2012.1079

\begin{abstract}
Icariin, the main active compound of the traditional Chinese medicine, Epimedium, is commonly used for the clinical treatment of osteoporosis. However, the precise molecular mechanism of the therapeutic effect of icariin has not been elucidated. The aim of this study was to examine the effect of icariin on cell viability, alkaline phosphatase (ALP) activity, the amount of calcified nodules, and to delineate the molecular mechanism of icariin-enhanced bone formation by investigating the expression of bone morphogenic protein-2 (BMP-2), Smad4, Cbfa1/Runx2, osteoprotegerin (OPG), receptor activator of nuclear factor $\kappa-B$ ligand (RANKL) and the OPG/RANKL ratio in the hFOB 1.19 human osteoblastic cell line. We found that icariin significantly increased the cell viability, the activity of ALP and the amount of calcified nodules in the hFOB 1.19 cells. Furthermore, we observed that icariin upregulated the expression of BMP-2, Smad4, Cbfa1/ Runx2, OPG, RANKL and the OPG/RANKL ratio. Our results indicate that icariin can modulate the process of bone formation via the BMP-2/Smad4 signal transduction pathway in hFOB 1.19 cells.
\end{abstract}

\section{Introduction}

Osteoporosis is a common disease characterized by a reduction of bone mass resulting from the negative balance between bone formation and bone destruction (1). It can occur at any age

Correspondence to: Professor Candong Li, Research Base of Traditional Chinese Medicine Syndrome, Fujian University of Traditional Chinese Medicine, 1 Huatuo Road, University Town, Minhou Shangjie, Fuzhou 350122, P.R. China

E-mail: fjzylcd@126.com

*Contributed equally

Key words: bone formation, osteoblast, icariin, osteoporosis and in any ethnic or racial group, although it is more common in post-menopausal women, and affects millions of people worldwide $(2,3)$. The most serious consequence of osteoporosis is fracture, which is associated with an increase in substantial morbidity, mortality and social costs. Early intervention, now possible with the help of some effective medications, may reduce the risk of first and recurrent fractures (4). However, the lack of reliable and effective drugs to cure osteoporosis-related fragility fractures remains an important global issue. Therefore, there is a clear clinical need to develop new bone anabolic agents for the prevention and treatment of osteoporosis. Natural products that have relatively fewer side-effects have been used clinically. Epimedium, one of the most frequently prescribed herbs, has been utilized in traditional Chinese medicine for the treatment of osteoporosis. Icariin $\left(\mathrm{C}_{33} \mathrm{H}_{40} \mathrm{O}_{15}\right.$; molecular weight, 676.67), a flavonol glycoside obtained from this herb, is believed to be the major active compound that accounts for its bone protective actions (Fig. 1) $(5,6)$.

Recently, icariin was found to be therapeutically effective in ovariectomized rats. It increases trabecular bone mineral density (BMD) and bone strength and prevents the suppression of serum Ca levels $(7,8)$. In addition, icariin has been shown to increase cell proliferation, differentiation, mineralization, osteocalcin secretion, as well as the expression levels of bone-related proteins in a dose-dependent manner in primary osteoblastic cells (9-11). These results suggest that icariin prevents bone loss by suppressing bone resorption and stimulating bone formation. However, the understanding of its precise mechanism of biological action in bone formation remains incomplete.

Bone is an active tissue that undergoes constant remodeling in which old bone is degraded by osteoclasts (bone-resorbing cells), and subsequently replaced by new bone formed by osteoblasts (bone-forming cells), via a process known as remodeling (12). Bone remodeling, an active and dynamic process, facilitates the repair of microdamage and provides calcium from bone stores for cellular functions. Osteoblasts are the obvious target for agents that aim to mediate bone anabolism $(13,14)$. A key signaling component in bone formation is bone morphogenic protein-2 (BMP-2), a member of the 
transforming growth factor- $\beta$ (TGF- $\beta$ ) superfamily $(15,16)$. BMP-2 signals via Smad4, which is a nuclear transcription factor that regulates the activity of TGF- $\beta$ ligands and plays an important role in bone formation (17). In the present study, we hypothesized that icariin can modulate the process of bone formation by the BMP-2/Smad4 signal transduction pathway. We assessed the direct effect of icariin on cell viability, alkaline phosphatase (ALP) levels and the amount of calcified nodules, as well as the expression of BMP-2, Smad4, Cbfa1/Runx2, osteoprotegerin (OPG), receptor activator of nuclear factor $\mathrm{\kappa}-\mathrm{B}$ ligand (RANKL) and the OPG/RANKL ratio in hFOB 1.19 cells in vitro, and investigated the possible molecular mechanism mediating its biological effect. We found that icariin enhanced the cell viability in a dose- and time-dependent manner. In addition, icariin treatment promoted the amount of calcified nodules in the hFOB 1.19 cells, which was accompanied by the upregulation of the expression of ALP, BMP-2, Smad4, Cbfa1/Runx2, OPG, RANKL and the OPG/RANKL ratio. Our findings suggest that icariin promotes the process of bone formation.

\section{Materials and methods}

Materials and reagents. Fetal bovine serum (FBS), Dulbecco's modified Eagle's medium (DMEM), and trypsin-EDTA were purchased from Hyclone Laboratories, Inc. (Logan, UT, USA). 3-(4,5-Dimethylthiazol-2-yl)-2,5-diphenyltetrazolium bromide (MTT) was obtained from the Sigma Chemical Co. (St. Louis, MO, USA). TRIzol reagent was purchased from Inc. (Grand Island, NY, USA). Monoclonal rabbit anti-human Smad4, Cbfa1/Runx2, and $\beta$-actin HRP secondary goat anti-rabbit antibodies were purchased from Abcam (Cambridge, MA, USA). Primers were synthesized by Sangon Biotech (Shanghai, China). Icariin (HPLC $\geq 98 \%$ ) was produced by Nanjing Zelang Medical Technological Co., Ltd. (Nanjing, China). Stock solutions of icariin were prepared by dissolving the icariin powder in DMSO to a concentration of $10^{-3} \mathrm{M}$, and stored at $-20^{\circ} \mathrm{C}$. The working concentrations of icariin were obtained by diluting the stock solution with the culture medium. The final concentration of DMSO in the medium was $<0.5 \%$.

Cell culture. The hFOB 1.19 human osteoblastic cell line obtained from the Insitute of Biochemistry and Cell Biology, Chinese Academy of Sciences (Shanghai, China) was cultured in DMEM, supplemented with $10 \%$ (v/v) FBS, penicillin $(100 \mathrm{U} / \mathrm{ml})$ and streptomycin $(100 \mu \mathrm{g} / \mathrm{ml})$ at $37^{\circ} \mathrm{C}$ in a humidified incubator with $5 \% \mathrm{CO}_{2}$. The medium was replaced every 3 days. At $80-90 \%$ confluence, the cells were seeded in 96- or 6 -well plates at a density of $1 \times 10^{5}$ or $3 \times 10^{3}$ cells/well, respectively, for different assays. The cells used in this study were subjected to $\geq 30$ cell passages.

Evaluation of cell viability by MTT assay. The hFOB 1.19 cell viability was assessed by MTT colorimetric assay. The cells were seeded in 96-well plates at a density of $1.0 \times 10^{5}$ cells/well, cultured for $24 \mathrm{~h}$ and starved for $24 \mathrm{~h}$ in serum-free DMEM medium. The cells were treated with icariin at various final concentrations $\left(10^{-15}, 10^{-12}, 10^{-9}\right.$ and $\left.10^{-6} \mathrm{M}\right)$ and the vehicle control cells were treated with $0.5 \%$ DMSO for $48 \mathrm{~h}$. In some experiments, the cells were treated with $10^{-9} \mathrm{M}$ of icariin for

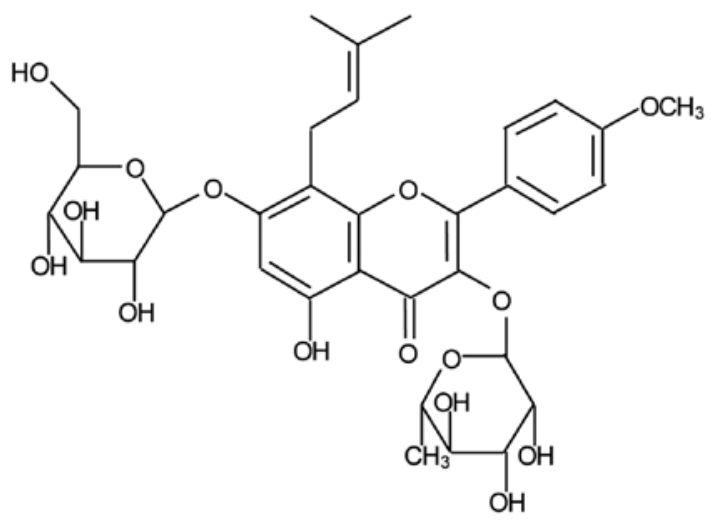

Figure 1. Chemical structure of icariin.

different periods of time. The medium was discarded and replaced with $10 \mu 1$ MTT [5 mg/ml in phosphate-buffered saline (PBS)]. After incubation at $37^{\circ} \mathrm{C}$ for $4 \mathrm{~h}$, the purple-blue MTT formazan precipitate was dissolved in $100 \mu \mathrm{l}$ DMSO and the cells were agitated for $10 \mathrm{~min}$. The absorbance at $490 \mathrm{~nm}$ was measured on an ELISA reader (Model EXL800; BioTek, Winooski, VT, USA).

Alizarin red $S$ staining for mineralization. Calcified nodules of the hFOB 1.19 cells were demonstrated by Alizarin red S staining. The cells were seeded in 48 -well plates at a density of $2 \times 10^{5}$ cells/well and cultured for $24 \mathrm{~h}$, and then treated with or without icariin. The medium was replaced every 3 days. After 14 days, the cell cultures were washed 3 times with PBS, fixed with formalin:methanol: $\mathrm{H}_{2} \mathrm{O}(1: 1: 1.5) 0.5 \mathrm{ml} /$ well for $30 \mathrm{~min}$ at room temperature, and then washed 3 times with double distilled water. The cells were stained with $0.1 \%$ Alizarin red S at $37^{\circ} \mathrm{C}$ for $30 \mathrm{~min}$, and washed 5 times with double distilled water and air-dried. The stained calcified nodules that appeared bright red in color were identified by light microscopy.

ALP activity assay. The cells were seeded in 48-well plates at a density of $2 \times 10^{5}$ cells/well and cultured for $24 \mathrm{~h}$, and then treated with or without icariin for $48 \mathrm{~h}$. Cells were harvested after treatment and lysed with $100 \mu 1$ Nonidet P-40 lysis buffer (20 mM Tris-HCl, pH 7.5, $150 \mathrm{mM} \mathrm{NaCl}, 1 \mathrm{mM} \mathrm{MgCl}, 1 \mathrm{mM}$ $\mathrm{CaCl}_{2}, 10 \%$ glycerol, $1 \%$ Nonidet P-40) supplemented with protease inhibitors [2 $\mu \mathrm{g} / \mathrm{ml}$ leupeptin, $2 \mu \mathrm{g} / \mathrm{ml}$ aprotinin and $1 \mathrm{mM}$ phenylmethylsulfonyl fluoride (PMSF)] by incubation on ice for $30 \mathrm{~min}$. The supernatant, centrifuged at $12,000 \mathrm{x}$ g and $4^{\circ} \mathrm{C}$ for $5 \mathrm{~min}$, was stored at $-80^{\circ} \mathrm{C}$ until analysis. Intracellular ALP activity was determined according to the manufacturer's instructions. Briefly, the sample was mixed with $1 \mathrm{ml}$ ALP reagent (Hitachi, Tokyo, Japan) and the absorbance change at $405 \mathrm{~nm}$ in $3 \mathrm{~min}$ was recorded. ALP activity was calculated as: $\operatorname{ALP}(\mathrm{U} / \mathrm{l})=($ total volume/sample volume $) \mathrm{x}$ (absorbance change in $3 \mathrm{~min} / 0.01875$ ). To normalize the result, bicinchoninic acid (BCA) protein assay was carried out and ALP activity was expressed as units of activity $(\mathrm{U}) \cdot 1^{-1} \cdot(\mathrm{mg} \text { protein })^{-1}$.

RNA extraction and real-time PCR analysis. After icariin treatment for $48 \mathrm{~h}$, total RNA from the cells was isolated with TRIzol reagent (Invitrogen). Oligo(dT)-primed RNA (5 $\mu \mathrm{g})$ was reverse-transcribed with SuperScript II reverse transcriptase 



Figure 2. Effect of icariin on cell viability in hFOB 1.19 cells. The hFOB 1.19 cell viability increased at each concentration, with significant statistical differences observed between the cells treated with icariin and the control cells (A) Cells were treated with the indicated concentrations of icariin for $48 \mathrm{~h}$ (B) Cells were treated with $10^{-9} \mathrm{M}$ of icariin for the indicated time periods Cell viability was determined by the MTT assay. Data are averages \pm SD (error bars) from at least 3 independent experiments. ${ }^{* *} \mathrm{P}<0.01$, statistically significant vs. control. C, control cells.

(Promega) according to the manufacturer's instructions. The sequences of the PCR primers for the amplification of BMP-2, Smad4, OPG, RANKL and $\beta$-actin transcripts were as follows: BMP-2 forward, 5'-CGG ACT GCG GTC TCC TAA-3' and reverse, 5'-GGA AGC AGC AAC GCT AGA AG-3', 68 bp; Smad4 forward, 5'-AAA GGT GAA GGT GAT GTT TGG GTC-3' and reverse, 5'-CTG GAG CTA TTC CAC CTA CTG ATC C-3', 268 bp; OPG forward, 5'-AGT ACG TCA AGC AGG AGT GCA AT-3' and reverse, 5'-CCA GCT TGC ACC ACT CCA A-3', 129 bp; RANKL forward, 5'-AGA GCG CAG ATG GAT CCT AA-3' and reverse, 5'-TTC CTT TTG CAC AGC TCC TT-3', $180 \mathrm{bp}$; and GAPDH forward, 5'-CAA CTA CAT GGT TTA CAT GTT C-3' and reverse, 5'-GCC AGT GGA CTC CAC GAC-3', 163 bp. PCR was carried out in a $20 \mu 1$ reaction mixture containing $10 \mu$ l iQTM SYBR-Green Supermix (Bio-Rad Laboratories, Hercules, CA, USA) and $0.5 \mu \mathrm{l}$ of cDNA template. PCR was performed in an ABI 7900 HT fast real-time PCR system (Applied Biosystems) using the following cycle parameters: 1 cycle of $95^{\circ} \mathrm{C}$ for $1 \mathrm{~min}$, and 40 cycles of $95^{\circ} \mathrm{C}$ for $20 \mathrm{sec}$, different temperatures for $20 \mathrm{sec}$ and $72^{\circ} \mathrm{C}$ for $18 \mathrm{sec}$. Upon completion, a melting curve was examined. Standard curves were generated using serially diluted solutions of cDNA derived from the control group sample. The target gene transcripts in each group sample were normalized on the basis of GAPDH.
Western blot analysis. The treated cells were harvested and lysed with Nonidet P-40 lysis buffer (20 mM Tris- $\mathrm{HCl}, \mathrm{pH} 7.5$, $150 \mathrm{mM} \mathrm{NaCl}, 1 \mathrm{mM} \mathrm{MgCl} 2,1 \mathrm{mM} \mathrm{CaCl}{ }_{2}, 10 \%$ glycerol, $1 \%$ Nonidet $\mathrm{P}-40$ ) supplemented with protease inhibitors ( $2 \mu \mathrm{g} / \mathrm{ml}$ aprotinin, $2 \mu \mathrm{g} / \mathrm{ml}$ leupeptin and $1 \mathrm{mM}$ PMSF) and phosphatase inhibitors $(1 \mathrm{mM}$ sodium orthovanadate, $10 \mathrm{mM}$ $\mathrm{NaF}$ ). Protein concentrations were determined using the BCA protein assay. Equal amounts of proteins were separated by SDS-PAGE on a $12 \%$ reducing gel at a constant voltage $(110 \mathrm{~V})$ for approximately $2 \mathrm{~h}$, and transblotted onto PVDF membranes. The non-specific binding sites on the membranes were blocked with $5 \%$ skimmed milk. The blots were probed with monoclonal rabbit anti-human Smad4 (1:2,000), Cbfa1/ Runx2 $(1: 1,000)$ and $\beta$-actin $(1: 1,000)$ antibodies overnight at $4^{\circ} \mathrm{C}$ with rocking, followed by incubation with goat antirabbit conjugated with horseradish peroxidase $(1: 2,000)$. The antigen-antibody complexes were then detected with enhanced chemiluminescence (ECL) reagent (Santa Cruz Biotechnology, Inc., USA). Bands were then quantified by scanning densitometry (170-8070 Molecular Imager ChemiDoc XRS System; Bio-Rad). Protein concentrations were determined using the Tocan 190 protein assay system and normalized to $\beta$-actin in the sample.

Statistical analysis. Data were analyzed using the SPSS package for Windows (version 13.0). Quantitative data were expressed as the means \pm standard deviation (SD). Statistical analysis of the data was performed with the Student's t-test and ANOVA. P-value $<0.05$ was considered to indicate a statistically significant difference.

\section{Results}

Effect of icariin on cell viability in hFOB 1.19 cells. Icariin $\left(10^{-12}, 10^{-9}\right.$ and $\left.10^{-6} \mathrm{M}\right)$ significantly increased cell viability by approximately $111.67 \pm 4.72,136.50 \pm 6.47$ and $123.17 \pm 4.49 \%$ in hFOB 1.19 cells compared to the control cells $(100 \pm 0.00 \%$, $\mathrm{P}<0.01$ ) (Fig. 2A). The cell viability with $10^{-9} \mathrm{M}$ of icariin at $24 \mathrm{~h}$ $(116.57 \pm 6.16 \%), 48 \mathrm{~h}(139.42 \pm 7.53 \%)$ and $72 \mathrm{~h}(143.91 \pm 5.13 \%)$ was significantly higher than that at $0 \mathrm{~h}(100 \pm 0.00 \%, \mathrm{P}<0.01)$ (Fig. 2B). These results indicate that icariin enhances osteoblastic cell viability in a dose- and time-dependent manner.

Effect of icariin on ALP activity and calcified nodules in hFOB 1.19 cells. The ALP activity in the hFOB 1.19 cells was increased by 1.09-, 1.21- and 1.13-fold when the cells were treated with icariin at the final concentrations of $10^{-12}, 10^{-9}$ and $10^{-6} \mathrm{M}$, respectively, significantly higher than that of the control cells $(\mathrm{P}<0.05)$ (Fig. 3). The calcified nodules appeared bright red in color by Alizarin red S staining (Fig. 4). Icariin at $10^{-12}, 10^{-9}$ and $10^{-6} \mathrm{M}$ stimulated the formation of calcified nodules significantly compared to the control cells. These results suggest that icariin promotes ALP expression and the formation of calcified nodules in hFOB 1.19 cells.

Effect of icariin on BMP-2, Smad4, OPG and RANKL $m R N A$ expression in $h F O B 1.19$ cells. Icariin induced a 1.24-, 1.38and 1.32-fold increase in BMP-2 mRNA expression $(\mathrm{P}<0.01)$ (Fig. 5A) and a 1.08-, 1.23- and 1.15-fold increase in Smad4 mRNA expression $(\mathrm{P}<0.05)$ (Fig. 5B). Furthermore, icariin 


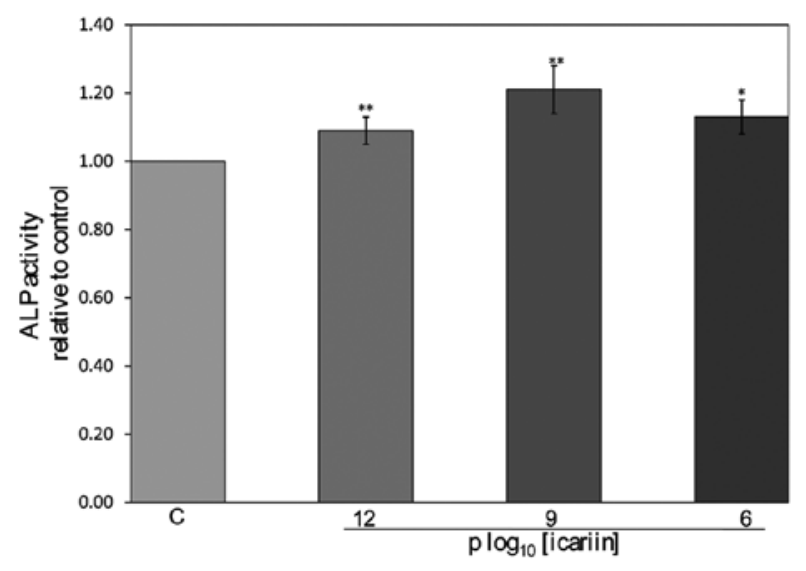

Figure 3. Effect of icariin on alkaline phosphatase (ALP) activities in hFOB 1.19 cells. The hFOB 1.19 cells were treated with or without icariin for $48 \mathrm{~h}$. Cell lysates were used for ALP activity measurement. Results were obtained from 3 independent experiments, and data are averages \pm SD (error bars), ${ }^{*} \mathrm{P}<0.05,{ }^{* *} \mathrm{P}<0.01$ vs. control. $\mathrm{C}$, control cells.

not only significantly increased OPG mRNA expression in hFOB 1.19 cells $(\mathrm{P}<0.01)$ (Fig. 5C), but also significantly increased RANKL mRNA expression in $\mathrm{hFOB} 1.19$ cells at all concentrations tested $(\mathrm{P}<0.01)$ (Fig. 5D). The overall effects of icariin on the OPG/RANKL mRNA expression ratio in hFOB 1.19 cells are shown in Fig. 5E. The results clearly indicated that icariin significantly increased the OPG/RANKL ratio in $\mathrm{hFOB} 1.19$ cells $(\mathrm{P}<0.05)$, suggesting that icariin enhances bone formation via its actions on OPG and RANKL expression.

Effect of icariin on Smad4 and Cbfal/Runx2 protein expression in hFOB 1.19 cells. To further explore the mechanism by which icariin regulates bone formation, we analyzed the protein expression levels of Smad4 and Cbfa1/Runx2 after icariin treatment using western blot analysis (Fig. 6A). Icariin $\left(10^{-12}\right.$, $10^{-9}$ and $10^{-6} \mathrm{M}$ ) significantly increased Smad4 expression $(0.42 \pm 0.06,0.76 \pm 0.07$ and $0.81 \pm 0.05)$ in the hFOB 1.19 cells compared to the control cells $(0.35 \pm 0.04, \mathrm{P}<0.05)$ (Fig. 6B). Icariin $\left(10^{-12}, 10^{-9}\right.$ and $\left.10^{-6} \mathrm{M}\right)$ significantly increased Cbfa1/ Runx2 expression $(0.41 \pm 0.04,0.71 \pm 0.05$ and $0.68 \pm 0.04)$ in the hFOB 1.19 cells compared to the control cells $(0.38 \pm 0.03$, $\mathrm{P}<0.01$ ) (Fig. 6C). Taken together, these results suggest that icariin modulates the process of bone formation via its effects on Smad4 and Cbfa1/Runx2 expression.

\section{Discussion}

In the present study, we systematically evaluated the osteoprotective effects and mechanism of actions of icariin in the hFOB 1.19 human osteoblastic cell line. Our results clearly demonstrate that icariin enhances the cell viability and increases the amount of calcified nodules, as well as increasing the expression ratio of OPG/RANKL in hFOB 1.19 cells. In addition, our results show that icariin upregulates the expression of ALP, BMP-2, Smad4, Cbfa1/Runx2, OPG and RANKL, suggesting that it promotes osteoblastic bone formation by the BMP-2/Smad4 signal transduction pathway.

Osteoporosis, a progressive disorder of aging bone, is a worldwide health problem with a high prevalence. Bone is a dynamic tissue whereby old bone is removed by osteoclasts and new bone is formed continuously by osteoblasts. Bone generation, maintenance and healing are complicated processes in which osteoblasts, osteoclasts, and osteocytes are known to play important roles (18). Multiple factors can cause the loss of bone mass, including increased bone turnover, which results in an imbalance of osteoclasts and osteoblasts at the bone remodeling process (19). Therefore, agents with an anabolic action on the bone may be effective in increasing the activity of osteoblasts and treating osteoporosis.
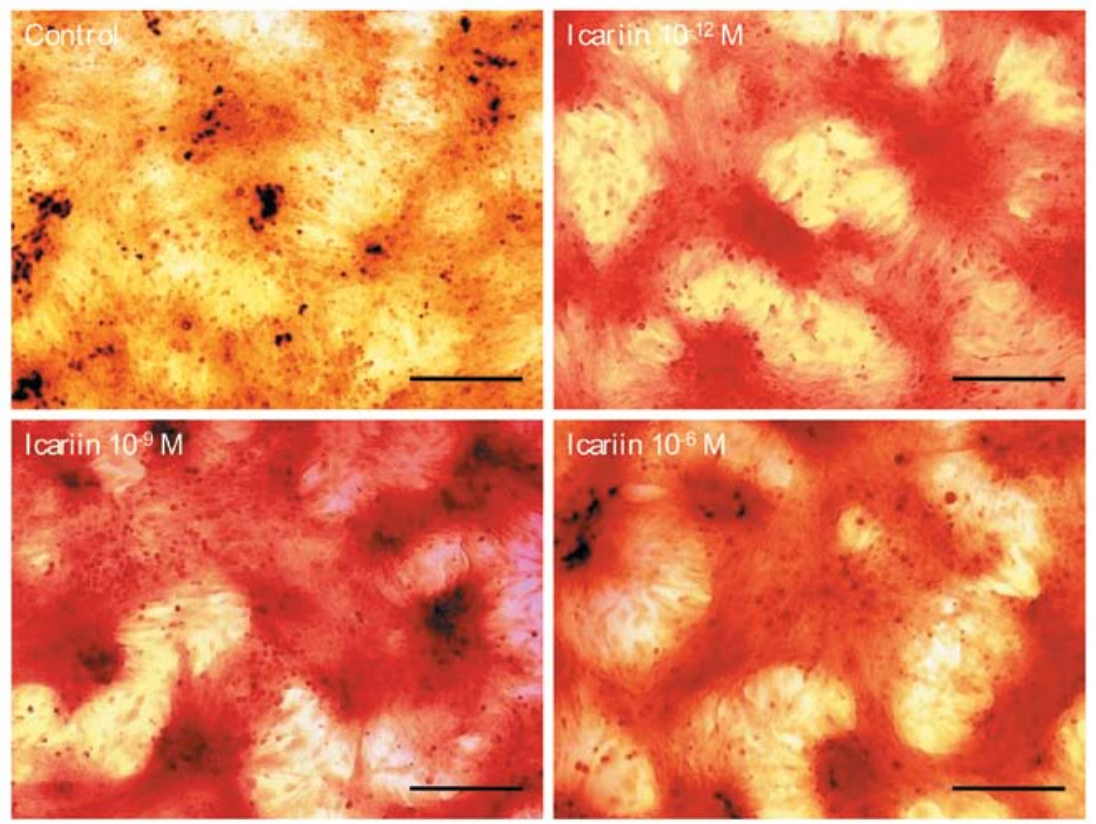

Figure 4. Effect of icariin on calcified nodules in hFOB 1.19 cells. The hFOB 1.19 cells were treated with or without icariin for 14 days. Alizarin red S staining for mineralization. The calcified nodules appeared bright red in color. 



Figure 5. Effect of icariin on BMP-2, Smad4, OPG, RANKL mRNA expression and the OPG/RANKL ratio in hFOB 1.19 cells. The hFOB 1.19 cells were treated with or without icariin for $48 \mathrm{~h}$. Total RNA was isolated and real-time PCR was performed to determine the mRNA expression levels of (A) BMP-2, (B) Smad4, (C) OPG, (D) RANKL and (E) OPG/RANKL, which were normalized to those of GAPDH. Results were obtained from 3 independent experiments, and data are averages $\pm \mathrm{SD}$ (error bars), ${ }^{*} \mathrm{P}<0.05 ;{ }^{* *} \mathrm{P}<0.01$ vs. control. C, control cells.
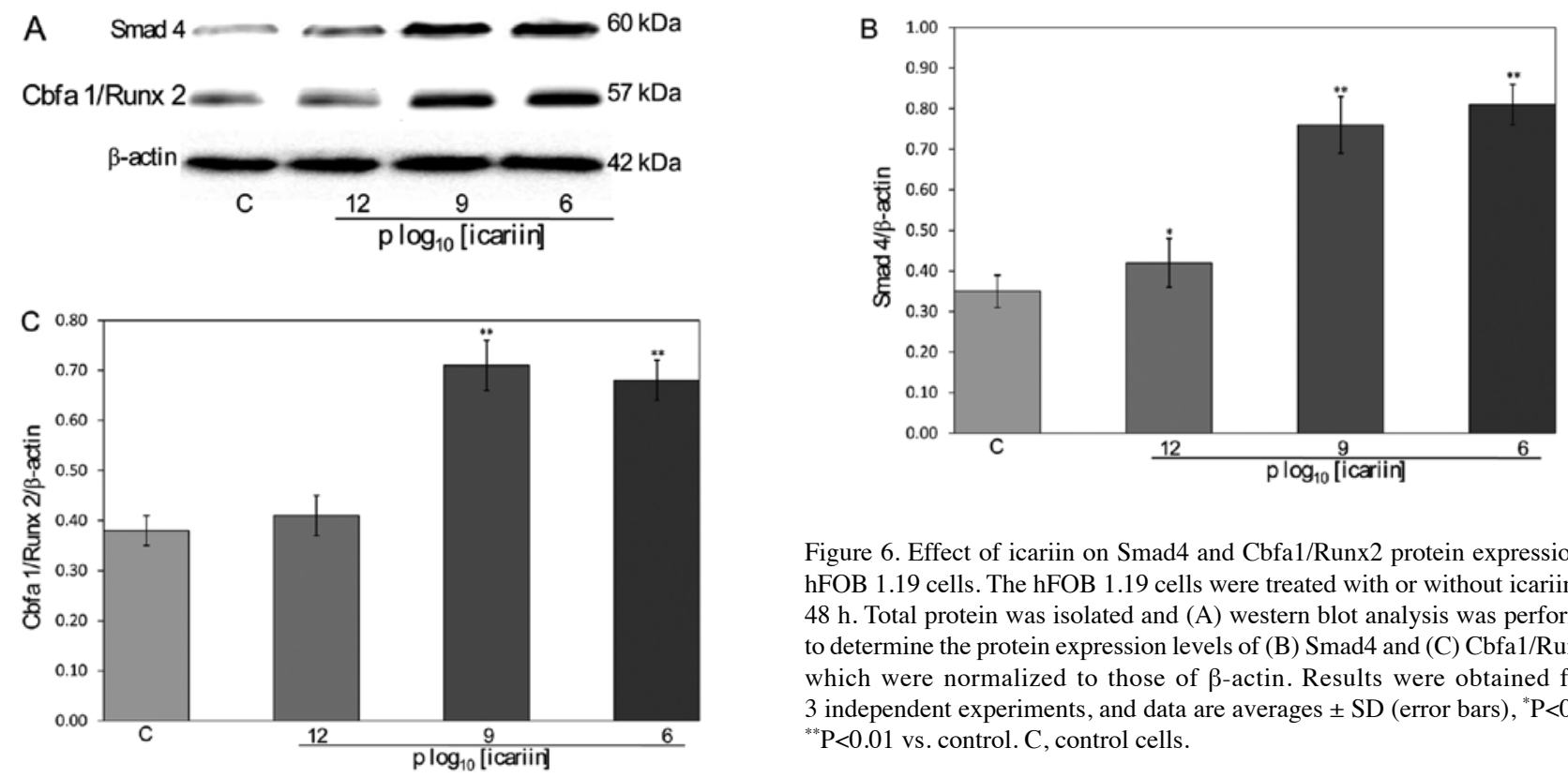

Figure 6. Effect of icariin on Smad4 and Cbfa1/Runx2 protein expression in hFOB 1.19 cells. The hFOB 1.19 cells were treated with or without icariin for $48 \mathrm{~h}$. Total protein was isolated and (A) western blot analysis was performed to determine the protein expression levels of (B) Smad4 and (C) Cbfa1/Runx2, which were normalized to those of $\beta$-actin. Results were obtained from 3 independent experiments, and data are averages $\pm \mathrm{SD}$ (error bars), ${ }^{*} \mathrm{P}<0.05$; ${ }^{* * *} \mathrm{P}<0.01$ vs. control. C, control cells. 
The study of Chinese herbs is worthwhile as this may lead to the discovery of certain agents which can stimulate the proliferation and differentiation of osteoblasts. Recently, Epimedium has received increased attention since many studies on animals and cell culture systems have indicated that icariin plays an important role in the prevention of osteoporosis $(20,21)$. Hence, in the present study, we explored the effect of icariin on the hFOB 1.19 human osteoblastic cell line.

The results of the present study confirm that icariin stimulates the proliferation of hFOB 1.19 cells in a dose- and time-dependent manner. Osteoblasts are derived from mesenchymal stem cells. The sequential expression of type I collagen, ALP and the deposition of calcium are known as molecular markers. Human osteoblasts cultured for $48 \mathrm{~h}$ in the presence of $10^{-12}, 10^{-9}$ and $10^{-6} \mathrm{M}$ of icariin exhibited a significant increase in ALP activity, and the formation of mineralized nodules increased significantly after the cells were cultured for 14 days in the presence of $10^{-12}, 10^{-9}$ and $10^{-6} \mathrm{M}$ icariin. As the appearance of ALP activity is an early phenotypic marker for mature osteoblasts, and mineralized nodule formation is a phenotypic marker for a later stage of osteoblast differentiation, our results suggested that icariin stimulated bone formation. Further study is required to clarify the possible additional effects of icariin on renal $\mathrm{Ca}$ transport that contribute to the conservation of bone mass in animal models of osteoporosis.

BMPs play important roles in the regulation of bone induction, repair and maintenance (22). BMP-2 has demonstrated a strong osteo-inductive capacity, and has been shown to induce the osteoblastic differentiation of various types of cells, including pre-osteoblasts, undifferentiated mesenchymal cells and bone marrow stromal cells (23). The function of BMP-2 is mediated by heterotetrameric serine/threonine kinase receptors and the downstream transcription factors, Smad1, 5 and 8 (24). After these transcription factors are phosphorylated on serine residues, they form a complex with Smad4 (a common mediator), and subsequently the complex is translocated into the nucleus to activate the transcription of Cbfa1/Runx2, thereby regulating bone metabolism (25). Our results indicated that the BMP-2, Smad4 and Cbfa1/Runx2 expression increased in the icariin-treated hFOB 1.19 cells.

Osteoblasts are recruited to the resorption area and osteoclasts are activated to resorb old bone in the bone remodeling process. OPG and RANKL are critical in determining osteoclastogenesis and bone homeostasis $(26,27)$. OPG blocks these effects and prevents bone resorption, whereas RANKL represents the osteoblast-derived factor required for osteoclast formation $(28,29)$. The levels of OPG and RANKL play important roles in the regulation of the formation of hFOB 1.19 cells. Our study indicates that OPG and RANKL mRNA expression increases after treatment with icariin. As its stimulatory effects on OPG mRNA expression were stronger than those on RANKL mRNA expression, the effects of icariin at $10^{-9}$ and $10^{-6} \mathrm{M}$ on the $\mathrm{OPG} / \mathrm{RANKL}$ ratio were also stimulatory. These results suggest that icariin promotes bone formation through its direct actions on modulating the expression of OPG and RANKL.

Icariin, an active ingredient identified in Epimedium, is commonly used for the treatment of osteoporosis in traditional Chinese medicine. The present study clearly demonstrates that icariin modulates the process of bone formation via the regulation of the BMP-2/Smad4 signal transduction pathway in $\mathrm{hFOB} 1.19$ cells. Our study provides the evidence to support the use of icariin as an effective candidate for the management of osteoporosis. Further studies are required to elucidate the mechanisms by which icariin protects against bone loss.

\section{Acknowledgements}

This study was supported by the National Natural Science Foundation of China (Grant no. 81102609), the Natural Science Foundation of Fujian Province (Grant no. 2011J05076) and the Youth Foundation of Fujian Provincial Health Bureau (Grant no. 2011-2-31).

\section{References}

1. Narayanan D, Anitha A, Jayakumar R, Nair SV and Chennazhi KP: Synthesis, characterization and preliminary in vitro evaluation of PTH 1-34 loaded chitosan nanoparticles for osteoporosis. J Biomed Nanotechnol 8: 98-106, 2012.

2. Przedlacki J: Strontium ranelate in post-menopausal osteoporosis. Endokrynol Pol 62: 65-72, 2011.

3. Padova G, Borzì G, Incorvaia L, et al: Prevalence of osteoporosis and vertebral fractures in acromegalic patients. Clin Cases Miner Bone Metab 8: 37-43, 2011.

4. Datta NS: Osteoporotic fracture and parathyroid hormone. World J Orthop 2: 67-74, 2011.

5. Qian G, Zhang X, Lu L, Wu X, Li S and Meng J: Regulation of Cbfa1 expression by total flavonoids of Herba epimedii. Endocr J 53: 87-94, 2006.

6. Qin L, Han T, Zhang Q, et al: Antiosteoporotic chemical constituents from Er-Xian Decoction, a traditional Chinese herbal formula. J Ethnopharmacol 118: 271-279, 2008.

7. Chen KM, Ma HP, Ge BF, et al: Icariin enhances the osteogenic differentiation of bone marrow stromal cells but has no effects on the differentiation of newborn calvarial osteoblasts of rats. Pharmazie 62: 785-789, 2007.

8. Huang J, Yuan L, Wang X, Zhang TL and Wang K: Icaritin and its glycosides enhance osteoblastic, but suppress osteoclastic, differentiation and activity in vitro. Life Sci 81: 832-840, 2007.

9. Mok SK, Chen WF, Lai WP, et al: Icariin protects against bone loss induced by oestrogen deficiency and activates oestrogen receptor-dependent osteoblastic functions in UMR 106 cells. Br J Pharmacol 159: 939-949, 2010.

10. Ma HP, Ming LG, Ge BF, et al: Icariin is more potent than genistein in promoting osteoblast differentiation and mineralization in vitro. J Cell Biochem 112: 916-923, 2011.

11. Zhang J, Li Y, Sun J, Liu C and Zhang D: Synergistic or antagonistic effect of MTE plus TF or icariin from Epimedium koreanum on the proliferation and differentiation of primary osteoblasts in vitro. Biol Trace Elem Res 143: 1746-1757, 2011.

12. Xiong $J$ and $\mathrm{O}^{\prime}$ Brien CA: Osteocyte RANKL: new insights into the control of bone remodeling. J Bone Miner Res 27: 499-505, 2012.

13. Mlakar SJ, Prezelj J and Marc J: Testing GSTP1 genotypes and haplotypes interactions in Slovenian post-/pre-menopausal women: novel involvement of glutathione S-transferases in bone remodeling process. Maturitas 71: 180-187, 2012.

14. Schmidt S, Post TM, Peletier LA, Boroujerdi MA and Danhof M: Coping with time scales in disease systems analysis: application to bone remodeling. J Pharmacokinet Pharmacodyn 38: 873-900, 2011.

15. Cao H, Ke Y, Zhang Y, Zhang CJ, Qian W and Zhang GL: Icariin stimulates MC3T3-E1 cell proliferation and differentiation through up-regulation of bone morphogenetic protein-2. Int $\mathrm{J}$ Mol Med 29: 435-439, 2012.

16. Matsubara T, Kida K, Yamaguchi A, et al: BMP2 regulates Osterix through Msx2 and Runx2 during osteoblast differentiation. J Biol Chem 283: 29119-29125, 2008.

17. Hsieh TP, Sheu SY, Sun JS, Chen MH and Liu MH: Icariin isolated from Epimedium pubescens regulates osteoblasts anabolism through BMP-2, SMAD4, and Cbfa1 expression. Phytomedicine 17: 414-423, 2010.

18. Swarnkar G, Sharan K, Siddiqui JA, et al: A novel flavonoid isolated from the steam-bark of Ulmus wallichiana planchon stimulates osteoblast function and inhibits osteoclast and adipocyte differentiation. Eur J Pharmacol 658: 65-73, 2011. 
19. Tabuchi M, Miyazawa K, Kimura M, et al: Enhancement of crude bone morphogenetic protein-induced new bone formation and normalization of endochondral ossification by bisphosphonate treatment in osteoprotegerin-deficient mice. Calcif Tissue Int 77: 239-249, 2005.

20. Peng S, Zhang G, He Y, et al: Epimedium-derived flavonoids promote osteoblastogenesis and suppress adipogenesis in bone marrow stromal cells while exerting an anabolic effect on osteoporotic bone. Bone 45: 534-544, 2009.

21. Hsieh TP, Sheu SY, Sun JS and Chen MH: Icariin inhibits osteoclast differentiation and bone resorption by suppression of MAPKs/NF- $\kappa \mathrm{B}$ regulated HIF-1 $\alpha$ and PGE(2) synthesis. Phytomedicine 18: 176-185, 2011.

22. Nojima J, Kanomata K, Takada Y, et al: Dual roles of smad proteins in the conversion from myoblasts to osteoblastic cells by bone morphogenetic proteins. J Biol Chem 285: 15577-15586, 2010.

23. Sotillo Rodriguez JE, Mansky KC, Jensen ED, et al: Enhanced osteoclastogenesis causes osteopenia in twisted gastrulationdeficient mice through increased BMP signaling. J Bone Miner Res 24: 1917-1926, 2009.

24. Wang L, Zhang X, Guo Y, et al: Involvement of BMPs/Smad signaling pathway in mechanical response in osteoblasts. Cell Physiol Biochem 26: 1093-1102, 2010.
25. Zhao J, Ohba S, Shinkai M, Chung UI and Nagamune T: Icariin induces osteogenic differentiation in vitro in a BMP- and Runx2-dependent manner. Biochem Biophys Res Commun 369: 444-448, 2008

26. Xiao Q, Chen A and Guo F: Effects of Icariin on expression of OPN mRNA and type I collagen in rat osteoblasts in vitro. J Huazhong Univ Sci Technolog Med Sci 25: 690-692, 2005.

27. Ma B, Zhang Q, Wu D, et al: Strontium fructose 1,6-diphosphate prevents bone loss in a rat model of postmenopausal osteoporosis via the OPG/RANKL/RANK pathway. Acta Pharmacol Sin 33: 479-489, 2012.

28. Lee JW, Iwahashi A, Hasegawa S, et al: Coptisine inhibits RANKL-induced NF- $\kappa$ B phosphorylation in osteoclast precursors and suppresses function through the regulation of RANKL and OPG gene expression in osteoblastic cells. J Nat Med 66: 8-16, 2012.

29. Enjuanes A, Ruiz-Gaspà S, Peris $\mathrm{P}$, et al: The effect of the alendronate on OPG/RANKL system in differentiated primary human osteoblasts. Endocrine 37: 180-186, 2010. 